\title{
EL TIEMPO EN EL REGLAMENTO 650/2012. ILUSTRACIONES DE LA PRÁCTICA ESPAÑOLA
}

\author{
Marta REQUEJo ISIDRO*
}

SUMARIO: 1 . INTRODUCCIÓN.-2. A MODO DE RECORDATORIO: DETERMINACIÓN DE LA LEY APLICABLE EN LOS SISTEMAS ANTERIOR Y VIGENTE.-2.1. El art. 9.8 CC.2.2. El Reglamento núm. 650/2012.-2.2.1. Principios de la nueva regulación.-2.2.2. En particular, la elección de ley. Identificación de una elección.-3. LA APLICACIÓN EN EL TIEMPO DEL REGLAMENTO 650/2012. ENTENDIENDO EL ART. 83.-3.1. Lógica del art. 83.-3.1.1. Apdos. 1 a 3.-3.1.2. El art. 83.4.-3.2. Interpretación del texto.-3.2.1. Con carácter general.-3.2.2. Aspectos singulares.—a) El art. 83.2. - b) Sobre el art. 83.3.—c) Sobre el art. 83.4.-4. LAS RESOLUCIONES DE LA DGRN.-4.1. Los supuestos.-4.2. Sobre la ley aplicable.-4.2.1. La ley aplicable en las Resoluciones de 2016 y 2018.-4.2.2. La Resolución de 10 de abril de 2017.-5. CONCLUSIÓN.

\section{INTRODUCCIÓN}

1. El 16 de agosto de 2012 entraba en vigor el Reglamento 650/2012 relativo a la competencia, la ley aplicable, el reconocimiento y la ejecución de las resoluciones, a la aceptación y la ejecución de los documentos públicos en materia de sucesiones mortis causa y a la creación de un certificado sucesorio europeo. A tenor del art. 83.1 el Reglamento se aplica a partir del 17 de agosto de 2015 a todas las sucesiones abiertas en o tras esa fecha, y ello con independencia de que medie una disposición mortis causa otorgada anteriormente. A día de hoy han trascendido varias resoluciones de la DGRN en aplicación del texto, de las cuales tres nos han llamado la atención hasta el punto de que podemos situarlas en el origen de estas páginas: la de 15 de junio de 2016, la de 4 de julio de 2016 (a la que cabe añadir la de 2 de marzo de 2018), y la de 10 de abril de $2017^{1}$. El motivo: ante

* Senior Research Fellow Max Planck Institute Luxembourg (marta.requejo@mpi.lu). El presente

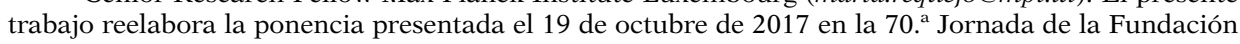
Coloquio Jurídico Europeo.

1 BOE núm. 175, de 21 de julio de 2016; BOE núm. 194, de 12 de agosto de 2016, y BOE, núm. 99, de 26 de abril de 2017, respectivamente. La RDGRN de 2 de marzo de 2018 se ha publicado en el $B O E$ núm. 69, de 20 de marzo de 2018. No somos los únicos a quienes las tres resoluciones han llamado la 
supuestos de hecho similares los razonamientos de la primera resolución sobre el Reglamento se retoman en las otras, para alcanzar, sin embargo, resultados distintos.

2. Que las soluciones sean distintas es llamativo: tiene interés en sí, y por eso merece que le dediquemos atención. Pero más allá de ello las Resoluciones ponen de manifiesto un problema que será frecuente (con tendencia a disminuir a medida que el pasa el tiempo) al amparo del nuevo régimen, como consecuencia del art. 83.1 ya mencionado: decisiones o actos del causante (una elección de ley, una disposición mortis causa) adoptados antes del 17 de agosto de 2015, que producen su efecto tras tal fecha porque el causante fallece ese día o más tarde, deberían quedar sometidos al régimen del Reglamento. El legislador europeo ha sido consciente de ello, y en el mismo precepto matiza la regla de aplicación temporal: con espíritu de respetar la voluntad del testador expresada antes de la aplicación del instrumento europeo, los siguientes apartados del art. 83 añaden al del Reglamento otros sistemas de DIPr, que entran en juego para mantener la validez de los actos mortis causa previos a él.

3. El mérito de este expediente es indudable, en particular desde la perspectiva de ordenamientos que, como el nuestro, han mantenido durante largo tiempo soluciones sobre la ley aplicable a la sucesión muy distintas a las que hoy están vigentes con carácter, además, universal. Sucede, sin embargo, que la norma no es ni fácil de entender, ni de aplicar. No lo es en sí misma considerada - veremos las distintas interpretaciones que sostiene la doctrina-; y se complica aún más como consecuencia de la remisión que hace al Capítulo III del Reglamento, en virtud de la cual incorpora las dificultades de comprensión y de aplicación de este.

4. Las resoluciones de la DGRN son el punto de partida de las páginas que siguen, cuyo objetivo final es evaluarlas. Para llegar hasta ahí comenzaremos con un recordatorio breve y simplemente instrumental del régimen vigente en España antes del Reglamento, y de este, en lo relativo a la determinación de la ley aplicable. Nos centraremos luego en el art. 83 Reglamento, como regla de transición de un momento (y de un régimen) a otro. Finalmente procederemos a la evaluación de las resoluciones.

atención: véase MARIÑo PARDO, F. M., «El testamento del ciudadano británico con residencia habitual en España tras el Reglamento europeo de sucesiones", en http://www.iurisprudente.com/search/label/ reglamento\%20europeo\%20de\%20sucesiones, 6 de octubre de 2016 (último acceso: 6 de junio de 2018), o la reciente publicación de YBARRA BorEs, A., «La sucesión de ciudadanos británicos en España tras la aplicación del Reglamento 650/2012», CDT, 2018 (1), pp. 466-488. 


\section{A MODO DE RECORDATORIO: DETERMINACIÓN DE LA LEY APLICABLE EN LOS SISTEMAS ANTERIOR Y VIGENTE}

\subsection{El art. $9.8 \mathrm{CC}$}

5. El DIPr español de la sucesión mortis causa ha estado presidido por el art. 9.8 $\mathrm{CC}^{2}$ desde la reforma del Título preliminar del mismo. Durante su vigencia el texto no ha experimentado mayor influencia del Derecho convencional (con la salvedad del Convenio de La Haya de 1961 sobre los conflictos de leyes en materia de forma de las disposiciones testamentarias, que por su objeto ha afectado ante todo al art. 11 CC, y a los arts. 732 y 733 del mismo cuerpo legal). Desde un punto de vista técnico la regla se caracteriza por la generalidad de su supuesto de hecho y la concreción temporal del punto de conexión. Desde la perspectiva de los valores que la inspiran los elementos a reseñar son el favor validitatis, y la preocupación por la unidad y universalidad, en todo caso con carácter limitado: el favor validitatis se articula en torno a dos conexiones, nada más ${ }^{3}$; de la unidad y universalidad de la sucesión no cabe hablar como principios absolutos, aunque solo sea porque el fraccionamiento es una consecuencia posible cada vez que la sucesión es testada ${ }^{4}$.

\subsection{El Reglamento núm. 650/2012}

\subsubsection{Principios de la nueva regulación}

6. Son ejes de la nueva reglamentación la unidad de la sucesión y el apoyo a la planificación sucesoria. A través de ambos se pretende un tercer objetivo típicamente europeo: la supresión de obstáculos a la libre circulación de personas ${ }^{5}$. La unidad se predica tanto en materia de ley aplicable como de competencia judicial internacional. Como regla —o aspiración, ya que el

2 La redacción actual del texto resulta del Decreto 1836/1974, BOE núm. 163, de 9 de julio de 1974, con la inclusión del apartado final ( Los derechos que por ministerio de la ley») por Ley 11/1990, de 15 de octubre, de reforma del Código Civil, en aplicación del principio de no discriminación por razón de sexo. El art. 9.8 CC no ha sido derogado: su aplicabilidad se mantiene para los conflictos internos, a menos que España decida aplicar el Reglamento igualmente en relación con estos casos, a lo que no está obligada a tenor del art. 38 del Reglamento.

3 En realidad una que, de concretarse en distintos ordenamientos como consecuencia de cambio de nacionalidad, se desdobla.

4 Álvarez GonzÁlez, S., "Dos cuestiones de actualidad en el reciente Derecho internacional privado español de sucesiones: los derechos del cónyuge supérstite y el reenvío», en ToRRES, T. (coord.), Estudios de Derecho Civil en Homenaje al profesor Francisco Javier Serrano García, Valladolid, 2004, pp. 131-157, esp. p. 151.

5 Lagarde, P., «Les principes de base du nouveau règlement européen sur les successions», Rev. Cr. Dr. Int. Pr., 2012, pp. 691-732, passim. Explica CARRAScosa GonZÁlez, J., "Reglamento sucesorio europeo y actividad notarial», $C D T, 2014$ (1), pp. 5-44, párr. 13, siguiendo a Ch. Baldus, que «las particularidades de los derechos nacionales de los Estados miembros en el sector sucesorio se emplean con 
Reglamento mismo introduce excepciones y acepta que otras puedan producirse de manera aleatoria- ${ }^{6}$ el conjunto de los bienes de la sucesión se rige por la misma ley, y un solo tribunal se pronuncia sobre la totalidad de las cuestiones de la dinámica sucesoria, desde la apertura hasta la partición, aplicando preferentemente su propia ley (forum-ius). Sobre la planificación sucesoria, se materializa a través de la incorporación al Reglamento de la autonomía de la voluntad, conflictual y material.

7. Tanto la unidad como el favor a la planificación de la sucesión son principios conocidos en España. No lo son, en cambio, todas las manifestaciones y concreciones que adoptan en el Reglamento, por lo que cabe augurar dificultades de adaptación al nuevo régimen. Aquí se desconocía el paralelismo forum-ius ${ }^{7}$ : la regla de competencia fue durante años la prevista en el art. 22.3 $\mathrm{LOPJ}^{8}$, conforme a la cual los tribunales españoles eran competentes en materia de sucesiones cuando el causante hubiera tenido su último domicilio en territorio español, o poseyera bienes inmuebles en España; en cambio la ley aplicable se determinaba siempre a través de la nacionalidad del causante. El Reglamento ha preferido la residencia habitual del causante al tiempo del fallecimiento: como expresión de proximidad, dado que la mayoría de las veces coincidirá con el centro de vida del de $\operatorname{cujus}^{9}$; y porque es la conexión que mejor permite el acoplamiento de las reglas de conflicto y de competencia judicial internacional, teniendo en cuenta los principios singulares a que deben responder además unas y otras. Se admite el desplazamiento de la residencia habitual, no obstante, en varios casos, siendo uno de ellos el de la elección de ley (art. 22). La professio habrá de recaer sobre la ley de la nacionalidad o nacionalidades del causante al tiempo de la elección, o del fallecimiento. Cualquiera de estas leyes tiene vocación para regir la sucesión en su totalidad en cuanto al fondo (véase el art. 23; y acerca de la extensión de la ley elegida, el art. 22.1, si bien no en la versión española) ${ }^{10}$. Existen no obstante inflexiones: en el caso de una disposición mortis causa, por ejemplo,

\footnotetext{
extrema frecuencia, para impedir la entrada en un Estado miembro de personas, empresas y agentes económicos que intervienen en este sector».

6 Véanse los arts. 24, 25 o 30 para lo primero; el art. 35 para lo segundo.

7 Cosa distinta es que finalmente, por motivos relacionados con la prueba del Derecho extranjero, la unidad se produjera igualmente.

8 Actualmente, y desde el 1 de octubre de 2015, art. 22 quáter letra g) LOPJ, introducido por la Ley Orgánica 7/2015, de 21 de julio.

9 Art. 21.1. Omitimos desarrollos relativos a la dificultad para identificar la residencia habitual, de los que ya hay ejemplos en la práctica en aplicación del Reglamento: Kammergerich Berlin, de 26 de abril de 2016, 1 AR 8/16; OLG Hambourg, de 16 de noviembre de 2016, $2 \mathrm{~W} \mathrm{85/16.} \mathrm{A} \mathrm{juicio} \mathrm{de} \mathrm{la} \mathrm{doctrina}$ —en España, CARRASCOSA GonZÁlez, J., loc. cit., nota 5, párr. 33, con más citas- la proximidad también justifica la professio iuris a favor de la ley nacional, si bien en este caso no debe leerse en clave objetiva sino subjetiva, en términos de costes «conflictuales» para el causante, a quien corresponde decidir si la aplicación de su ley nacional comportará menos costes que la de la residencia habitual. A nuestro juicio ello no es totalmente cierto: la optio iuris por la ley nacional tiene que ver con costes conflictuales pero también, y tanto o más, con el contenido (facultades de disponer) del ordenamiento en cuestión.

${ }_{10}$ Compárese con el texto en inglés o francés: "A person may choose as the law to govern his succession as a whole», "Une personne peut choisir comme loi régissant l'ensemble de sa succession». Sobre otras divergencias en el texto castellano del Reglamento, véase nota 33.
} 
su admisibilidad y validez se evalúan a la luz de la «ley sucesoria anticipada», que es la de la residencia habitual al tiempo del otorgamiento, como si el causante hubiera fallecido en ese momento (art. 24); pero las legítimas se regulan por la ley sucesoria, y no por la ley sucesoria anticipada (art. 23). Por otra parte, el alcance de cualquier ley de la sucesión - ya sea objetivamente aplicable, ya elegida, para la totalidad o solo para lo contemplado en los arts. 24 y 25-, puede verse modificado por la intervención de las reglas especiales previstas en los arts. 29 a 33.

\subsubsection{En particular: la elección de ley. Identificación de una elección}

8. La consagración en el Reglamento de la autonomía de la voluntad conflictual dota de gran importancia práctica a la cuestión de cómo se establece si hubo elección de ley. A partir de ahí, en segundo término, surge la cuestión de su validez ${ }^{11}$.

9. A tenor del art. 22 del Reglamento la elección de ley deberá hacerse expresamente en forma de disposición mortis causa, o resultar de los términos de una disposición de ese tipo. Ha existido cierta discusión entre los autores sobre si la segunda posibilidad se identifica con una elección tácita, lo que algunos descartan por motivos de seguridad jurídica ${ }^{12}$.

10. El reconocimiento de una elección de ley que no es expresa planteará dificultades y dudas. El propio Reglamento solo ofrece un ejemplo (un indicio, que no autoriza como conclusión necesaria la de que ha habido elección $)^{13}$ en su cdo. 39: la referencia en la disposición mortis causa a instituciones específicas de la ley del Estado de la nacionalidad del causante. Es típico en los autores aludir al trust testamentario anglosajón ${ }^{14}$, pero valdría cualquier otra: mejor cuanto más característica y, sobre todo, si exclusiva del ordenamiento en cuestión. Lo mismo se predica de expresiones típicas del Derecho sucesorio de cierto ordenamiento ${ }^{15}$, así como de la redacción

11 En la práctica la existencia y la validez de la elección que no es expresa se confunden en cierta medida, porque solo se reconoce como tal elección la que responde a un comportamiento concluyente con las características exigidas por el propio sistema.

12 LAGARDE, P., loc. cit., nota 5, párr. 31, siguiendo a M. Goré. En la doctrina el adjetivo alternativo a «tácita» parece ser "concluyente»: utiliza el primer término BonOMI, A., «Art. 22», en BonOMI, A. y WAUTELET, P., Le droit européen des successions, Bruselas, Bruylant, 2016, párrs. 56 y ss.; KoHLER, C., «L'autonomie de la volonté en droit international privé: un principe universel entre libéralisme et étatisme», Rec. des Cours (formato libro de bolsillo), vol. 19, p. 133. A una elección "concluyente» se refiere BAJONS, E. M., "Internationale Zuständigkeit und anwendbares Recht in Erbsachen», en ScHAUER, M. y Scheuba, E. (eds.), Europäische Erbrechtsverordnung, Viena, Manz, 2012, pp. 29-41, esp. p. 34.

13 DöRnER, H., «EuErbVO: Die Verordnung zum Internationalen Erb- und Erbverfahrensrecht it in Kraft!», Zeitschrift für Erbrecht und Vermögensnachfolge, 2012, núm. 10, pp. 505-513, esp. p. 511.

14 Por ejemplo, Davì, A. y ZanobetTI, A., Il nuovo diritto internazionale privato europeo delle successioni, Turín, 2014, p. 69; CARRAscosa GonZÁlez, J., El Reglamento Sucesorio Europeo 650/2012, de 4 de julio 2012. Análisis crítico, Comares, 2014, Sección 3. ${ }^{\text {a }}$, párr. 20, p. 139; GoRÉ, M., "La professio iuris», Defrénois, 15-30 de agosto de 2012, pp. 762-766, párr. 9.

15 Fischer-CzermaK, C., "Anwenbares Recht», en Schauer, M. y Scheuba, E. (eds.), Europäische Erbrechtsverordnung, Viena, Manz, 2012, pp. 43-55, esp. p. 48. 
del testamento siguiendo las pautas de un determinado sistema, o el uso de una lengua determinada ${ }^{16}$, por cuanto todos ellos son elementos del texto. $\mathrm{Al}$ margen de ellos - $\mathrm{O}$ incluso en su presencia - va a ser preciso interpretar la disposición sucesoria que presuntamente abriga la elección a la luz de la ley competente, que es la ley sucesoria anticipada a tenor del art. 26.1.d) ${ }^{17}$. Modelos previos de optio iuris en el Derecho europeo, como son el Reglamento Roma I ${ }^{18}$ en su art. 3, y el Reglamento Roma $\mathrm{II}^{19}$ en su art. 14, son de utilidad limitada: por un lado, por la diferencia esencial entre las materias ${ }^{20}$. Por otro, porque la redacción de aquellos preceptos difiere sensiblemente de la del art. 22 del Reglamento 650/2012, en particular por la exigencia en ellos de que la elección resulte «de manera inequívoca» de los términos del contrato (Roma I) o de las circunstancias del caso (ambos). Ninguno de estos dos elementos consta en el Reglamento de sucesiones, lo que puede apuntar a la voluntad de ser generoso en la identificación de la elección (por eso no se circunscribe a la que se desprenda inequívocamente del texto) ${ }^{21}$, al tiempo que se evita recurrir a datos externos cuya delimitación apriorística, con vistas a lograr una interpretación uniforme del texto legal, resultaría harto complicada.

11. La doctrina está dividida, por lo demás, acerca de si cabe atender a ciertos datos como auxiliares para identificar una professio iuris que "transparaît du texte de l'acte de dernière volonté de manière incomplète», o para apoyar o corroborar una indicación contenida en el texto ${ }^{22}$. Entre ellos cabe citar el lugar de otorgamiento de la disposición, o la nacionalidad

16 A nuestro juicio la lengua no puede ser determinante en los testamentos redactados a dos columnas, cada una en un idioma.

17 La admisibilidad y las condiciones de una elección no expresa están reguladas en el Reglamento como bien indica, por todos, DutTA, A., «Art. 22», Münchener Kommentar, Band 10 (Internationales Privaterecht I), 2015, párr. 14; pero más allá de lo que se deriva del mismo, si fuera necesario interpretar el texto de la disposición mortis causa para determinar si hay elección, y en qué términos y su alcance, los criterios jurídicos a retener vendrán dados por la ley sucesoria anticipada. También RIPOLL SolER, A., «Hacia un nuevo modelo de planificación sucesoria notarial», Revista de Derecho Civil, vol. III, 2016, núm. 2, pp. 23-64, bajo 4.2.

18 Reglamento (CE) 593/2008, del Parlamento Europeo y del Consejo, de 17 de junio, sobre la ley aplicable a las obligaciones contractuales.

19 Reglamento (CE) 864/2007, del Parlamento Europeo y del Consejo, de 11 de julio, relativo a la ley aplicable a las obligaciones extracontractuales.

20 Lechner, K., "Art. 83», en GeImer, R. y Schütze, R. A., Internationaler Rechtsverkehr in Zivilund Handelssachen, Munich, C. H. Beck, Band III, actualizado a febrero de 2018, párr. 11. El autor no desarrolla más esta afirmación, pero entendemos que se refiere a que los principios que rigen la interpretación son diferentes habida cuenta de que la elección no es - por regla - unilateral en los Reglamentos Roma I y Roma II; y es posible para las partes originales una vez entablado el litigio, para los aspectos que en él se discutan.

${ }^{21}$ En opinión de LECHNER, K., loc. últ. cit., la ausencia del adverbio es querida. Véase otra opinión en CARrascosa GonzÁlez, J., op. cit., nota 14, p. 139, siguiendo a G. Kühne.

22 Davi, A. y Zanobetti, A., «Il nuovo diritto internazionale privato delle successioni nell'Unione Europea», $C D T, 2013$ (2), pp. 5-139. A favor, BonOMI, A., loc. cit., nota 12, párr. 61. En contra, DAMASCELLI, D., «I criteri di collegamento impiegati dal regolamento n. 650/2012 per la designazione della legge regolatrice della successione a causa di morte», en Franzina, P. y LEANDro, A. (eds.), Il diritto internazionale privato europeo delle successioni mortis causa, Milán, Giuffrè, 2013, pp. 87-103, esp. p. 102; Goré, M., loc. cit., nota 14. 
del notario (que suele coincidir con el criterio precedente, pero que solo será relevante si es la del testador, por cuanto la elección está limitada a esta ley). Aunque no de forma aislada, estos elementos han sido empleados para establecer la ley aplicable bajo la Ley suiza de DIP de 1987, así como en aplicación del art. 25 EGBGB alemana ${ }^{23}$. En el primero de los casos, además, se tuvieron en cuenta hechos externos a la disposición por causa de muerte para apoyar la convicción de la autoridad sobre la voluntad del causante: así, sus declaraciones orales sobre su voluntad de que se aplicara un ordenamiento y no otro, en respuesta a una advertencia del notario sobre el contenido de ambos; o la elección hecha en testamentos previos ${ }^{24}$. En nuestra opinión, a tenor del texto del Reglamento es dudoso que quepa admitir estas prácticas.

12. Se discute también, en fin, si para poder concluir que hubo elección de ley es precisa la disposición psicológica del causante: la conciencia de estar eligiendo, y la voluntad de hacerlo ${ }^{25}$. A nuestro juicio la respuesta afirmativa está implícita en el cdo. 40 cuando indica que: «Debe corresponder [...] a la ley elegida determinar la validez material del acto de la elección, es decir, si cabe considerar que la persona que llevó a cabo la elección comprendió lo que estaba haciendo y consintió en ello» ${ }^{26}$. Es frecuente en la doctrina, no obstante, una actitud indulgente en cuanto al primer elemento, la conciencia, hasta el punto de excluir la necesidad de que el de cujus conozca el conflicto de leyes; e incluso la de este mismo ${ }^{27}$. Ello permite hablar de elección aun cuando en el momento del otorgamiento el supuesto careciera de cualquier elemento de internacionalidad - por lo que no cabía plantearse la aplicabilidad de un ordenamiento extranjero- , si el mismo concurre más adelante (el causante modificó su residencia habitual trasladándola al extranjero). Así se posibilita conservar una disposición que sería inválida conforme a la ley objetivamente aplicable ${ }^{28}$. Los autores insisten en todo caso en que debe concurrir la voluntad del causante de que se aplique cierta ley, y desprenderse del

${ }^{23}$ Véanse las citadas por Fontanellas Morell, J. M., «La forma de la designación de ley en la propuesta de reglamento europeo en materia de sucesiones", REDI, 2011, pp. 123-144, nota al pie núm. 48. A ellas cabe añadir las decisiones del OLG Hamm, de 22 de julio de 2014, Az 15 W 138/14, y la del OLG Schleswig-Holstein, de 25 de abril de 2016, 3 Wx 122/15.

24 Sentencia del Tribunal Federal suizo, de 3 de septiembre de 1998, en loc. últ. cit.

$25 \mathrm{O}$, al menos, la voluntad de que la sucesión se rija por una ley determinada, aunque no se acompañe de la conciencia de estar eligiendo, porque no exista tampoco la de que podrían aplicarse varios ordenamientos.

26 Otra lectura en BonOmi, A., loc. cit., nota 12, párr. 62.

27 Bonomi, A., loc. últ. cit.; DuTTA, A., loc. cit., nota 17, párr. 14, con más referencias. En España es lo que se desprende de ÁlvAREZ GonZÁLEZ, S., «Las legítimas en el reglamento sobre sucesiones y testamentos», $A E D I P r, 2011$, pp. 369-406, párr. 12, donde dice «es un elemento a mi juicio especialmente idóneo para la tutela de las expectativas de quien, aun no siendo consciente de la posibilidad de elección de ley, sí dispone de forma cierta [...] conforme a su ley nacional». También es esta la opinión que prevalece en relación con los ordenamientos que como el suizo admiten la professio iuris: véanse las referencias citadas POR DAVİ, A. y ZANOBETTI, A., op. cit., nota 14, en nota al pie núm. 67, donde recuerdan que el Tribunal Supremo Federal tiene, no obstante, otra actitud. La conciencia del conflicto de leyes era también un requisito en el DIPr alemán: OLG Frankfurt a.M., 29 de julio de 1997, IPRspr., 1997, núm. 122.

28 Bonomi, A., loc. últ. cit., párr. 63; DutTA, A., loc. cit., nota 17, párr. 14. 
texto: no cabe, por ejemplo, que los herederos acuerden que hubo elección a través de un pacto sobre la interpretación del texto ${ }^{29}$.

13. Sobre el segundo elemento, esto es, la voluntad de elegir entre varios ordenamientos, decae lógicamente si se elimina la exigencia de conciencia sobre el conflicto de leyes. No obstante, puede admitirse que el causante que dispone mortis causa respetando las condiciones de forma y fondo de su ley nacional está indicando su voluntad de que tal ley sea aplicada, al margen de la consideración de cualquier otra; en todo caso, ello debe derivarse de una disposición mortis causa. En este sentido hay que insistir en que son cosas distintas la elección tácita y la hipotética o la presunta, así como la ficción de elección de ley; el Reglamento no admite las primeras, y la tercera solo en el marco del art. $83.4^{30}$, como veremos.

\section{LA APLICACIÓN EN EL TIEMPO DEL REGLAMENTO 650/2012. ENTENDIENDO EL ART. 83}

14. A partir de la fecha de aplicación del Reglamento el operador jurídico español deberá manejar un sistema que presenta notables diferencias con aquel al que venía acostumbrado. Ello comprende el art. 83, bajo el título «Disposiciones transitorias» ${ }^{31}$.

\subsection{Lógica del art. 83}

\subsubsection{Apdos. 1 a 3}

15. El art. 83.1 del Reglamento establece la no retroactividad del instrumento: se aplicará a todas las sucesiones que se abran el o tras el 17 de agosto de 2015. La fecha de entrada en vigor del Reglamento es, no obstante, anterior: conforme al art. 84, a los veinte días de su publicación en el DOUE el 27 de julio de 2012. Se creó así una etapa interina en la que existía certeza sobre cuáles serían las reglas futuras, mientras permanecían vigentes las previas —salvo una decisión unilateral de aplicación anticipada de aquellas por parte de los Estados miembros-. Este periodo debería servir a la transición a un régimen que introduce importantes novedades en todos los Estados miembros, cualquiera que fuera el punto de partida.

16. Es el hecho mismo del cambio en el régimen de la sucesión internacional lo que justifica los apdos. 2 a 3 en el art. 83 -mientras que el apdo. 4

29 DutTA, A., loc. cit., nota 17, párr. 14.

30 Bonomi, A., loc. últ. cit., párr. 59; id., «Il regolamento europeo sulle successioni», Riv. Dir. Int. Pr. Pr., 2013, pp. 293-324, esp. p. 313; LechNER, K., loc. cit., nota 20, párr. 12; DuTTA, A., loc. cit., nota 17, párr. 14.

31 La búsqueda sobre la aplicación de este texto en otros Estados miembros arroja por el momento resultados muy pobres; la mención suele hacerse solo para indicar que el Reglamento no es aplicable: véase, por ejemplo, en Austria la decisión del OGH de 28 de junio de 2016, 2Ob105/15b. 
responde a una lógica particular que explica su tratamiento separado en este estudio-. Como ha expresado la doctrina, la estructura básica del DIPr nacional en materia sucesoria suele poseer una larga tradición con la que la población está familiarizada — aun de forma inconsciente-, y en la que confía. Que un cambio de residencia habitual conlleve un cambio en la ley aplicable, como ocurre actualmente a tenor del art. 21 del Reglamento, era algo con lo que los ciudadanos no contaban; de ahí que la regla de Derecho transitorio debiera responder, en primer término, al objetivo de conservar en la mayor medida posible la validez de las disposiciones mortis causa realizadas previamente, incluyendo en su caso una elección por el causante ${ }^{32}$. La suerte de una elección de ley o de foro previa a la fecha de aplicación del Reglamento se regula en el art. 83.2; la de una disposición por causa de muerte, en el siguiente apartado ${ }^{33}$.

17. Se ha sostenido en el pasado que las expectativas del causante sobre el DIPr aplicable a su disposición mortis causa no merecen atención, y ello, porque la ley aplicable no se concreta hasta el fallecimiento; mientras tanto es un estatuto "flotante» ${ }^{34}$. A nuestro juicio, esta afirmación, cierta en general, puede verse en entredicho cuando el sistema permite el individuo anticiparse y elegir antes de su muerte el ordenamiento que será aplicable, fijándolo. El objetivo primero de permitir la elección es eliminar la incertidumbre ligada a un punto de conexión mutable (conflicto móvil); pero también se genera confianza frente al cambio de la norma de conflicto misma, aun cuando su respeto no está totalmente garantizado y deba el causante mientras viva estar atento a posibles modificaciones del régimen conflictual.

18. El art. 83 en sus apdos. 2 y 3 es una manifestación de la opción del propio Reglamento por la anticipación o planificación sucesoria, que como vimos es un eje del sistema, y que en este precepto alcanza sus máximas consecuencias. El art. 83 va mucho más lejos de lo que requeriría respetar las previsiones del causante que otorgó un testamento antes del 17 de agosto de 2015: no solo se mantiene aquello que fuera válido a la luz del régimen vigente al tiempo del otorgamiento, sino que actos inválidos pueden quedar sanados $^{35}$, y ello incluso cuando tal invalidez fuera o pudiera haber sido conocida por el causante; el Reglamento no distingue en función del carácter razonable o irrazonable, legítimo o ilegítimo de estas expectativas ${ }^{36}$.

32 Lechner, K., loc. cit., nota 20, párr. 2.

33 En castellano el art. 83.3 se refiere en primer lugar a la admisibilidad y la validez de una disposición mortis causa, pero alude más adelante al momento «en que se hizo la elección» (cursiva añadida). Por coherencia — también con otras versiones lingüísticas del Reglamento- damos por hecho que se trata de un error de traducción.

34 Tomamos la expresión de Hess, B., Intertemporales Privatrecht, Mohr Siebeck, 1998, pp. 223-224 ( Schwebestatut»). Véase también Roubier, P., Le droit transitoire. Conflits des lois dans le temps, Dalloz, reimpr. 2008, pp. 309-314. La misma idea rige en relación con el Derecho material: véase por ejemplo la DT 12 del CC de 1889.

35 Entre otros muchos autores BARNICH, L., «Présentation du Règlement succesoral européen», en NuYTs, A. (coord.), Actualités en droit international privé, Bruylant, 2013, pp. 7-33, esp. p. 10; LECHNER, K., loc. cit., nota 20, párr. 5.

36 Wautelet, P., «Art. 83», en Bonomi. A. y Wautelet, P., Le droit européen des successions, Bruselas, Bruylant, 2016, párr. 6 (en p. 963) utiliza la expresión «attentes légitimes des justiciables». Sin 
19. El Reglamento europeo no es único en el sentido indicado: conforme al art. 22 del Convenio de La Haya de 1 de agosto de 1989 sobre la ley aplicable a las sucesiones por causa de muerte, el mismo se aplicará en cada Estado contratante a las sucesiones de las personas cuyo fallecimiento se produzca después de su entrada en vigor para dicho Estado; pero cuando el difunto hubiera designado la ley aplicable a su sucesión en cualquier momento anterior a la entrada en vigor del Convenio en dicho Estado, la citada designación se considerará válida si cumple los requisitos previstos en el art. 5. El Informe al Convenio indica que "the paragraphs 2 and 3 were not intended by the Sixteenth Session to render invalid a designation which under the law of the forum (assuming the Convention did not exist) is valid. The Convention is intended to be enabling; paragraphs 2 and 3 state, "that designation is to be considered valid if it complies with" Article 5 or Article 11, as the case may be. The intent is that these paragraphs may actually validate designations which in the absence of the Convention would have been invalid» ${ }^{37}$.

20. Es también interesante recordar el origen y la evolución del Reglamento como claves para una correcta comprensión de este punto. La propuesta de la Comisión, en su art. 50, se limitaba a la validez de una elección que lo fuera conforme al propio Reglamento ${ }^{38}$. Dado que la aplicación de este se preveía para un tiempo (entonces aún no fijado) después de la entrada en vigor $^{39}$, cabía sostener que la Comisión tenía en mente ese periodo interino, en el cual un causante podría realizar una elección de ley ya conforme a las reglas futuras en previsión de fallecer después de la fecha en que las mismas serían aplicables, asumiendo el riesgo de que el óbito sucediera antes. De este modo se satisfacía la necesidad de disponer de tiempo para la transición al nuevo régimen. Es el Parlamento el que quiso extender la aplicabilidad del Reglamento a un pasado anterior: en su enmienda núm. 116 al art. 50 la designación de ley aplicable conforme a las condiciones contempladas en el propio Reglamento sería válida aún realizada en «el periodo anterior $a$ su entrada en vigor» ${ }^{40}$. La adición de más posibilidades para preservar una elección de ley se debe igualmente al Parlamento, si bien en la primera redacción propuesta no se concretaban aún los puntos de conexión que serían alternativos al propio Reglamento. El texto era respetuoso con la situación vigente en cada Estado miembro; la elección de ley válida «en los Estados miembros en los que fuese válida cuando se realizó» se mantendría ${ }^{41}$. Algo similar se esta-

\footnotetext{
embargo, esa restricción no consta en el Reglamento; el mismo autor, párr. 9 (en p. 966), admite que «le mécanisme dépasse la protection des simples attentes subjectives des personnes concernées, pour acquérir une véritable dimension objective».

37 De Donovan W. y Waters, M., Actes et documents de la Seizième session (1988), t. II, párr. 134, redonda añadida.

38 Art. 50.2, $\operatorname{COM}(2009) 154$ final, de 14 de octubre de 2009.

39 Art. 51.

40 Proyecto de informe sobre la propuesta de Reglamento del Parlamento Europeo y del Consejo relativo a la competencia, la ley aplicable, el reconocimiento y la ejecución de las resoluciones y los actos auténticos en materia de sucesiones y a la creación de un certificado sucesorio europeo, Comisión de Asuntos Jurídicos, 2009/0157(COD), de 23 de febrero de 2011. Cursiva añadida.

${ }^{41}$ Enmienda 118.
} 
blecía para una disposición testamentaria ${ }^{42}$ : el Parlamento introdujo la idea de que una disposición conforme al ordenamiento - incluido el DIPr- que habría sido aplicable en el momento del otorgamiento no se vería afectada por virtud del Reglamento ${ }^{43}$. Además, la disposición testamentaria inválida realizada antes de la fecha de aplicación del Reglamento, entendiendo por ello también el periodo anterior a su entrada en vigor, quedaría sanada si se hubiera redactado conforme al Reglamento mismo ${ }^{44}$.

21. La fórmula finalmente adoptada, el actual art. $83^{45}$, es apta para producir la siguiente consecuencia: separar los actos de elección de ley y las disposiciones mortis causa del régimen jurídico vigente al tiempo de su otorgamiento - por tanto, del régimen al amparo del cual se realizaron-. Ambos (elección y disposición por causa de muerte) podrán ser declarados válidos por el mero hecho de serlo a la luz del Reglamento, esto es, de un sistema que no era aplicable en el momento de elegir o disponer; o del ordenamiento de un Estado miembro que no era el que correspondía aplicar. Su validez, en definitiva, es posible «por accidente» ${ }^{46}$, independiente de la suerte que les deparara el régimen que las autoridades de cada Estado miembro estaban obligadas a respetar al tiempo del otorgamiento ${ }^{47}$. Ello no deja de ser llamati$\mathrm{vo}^{48}$, en particular en relación con la elección de ley, si se considera que pocos Estados miembros la admitían antes del Reglamento y que si lo hacían era, en general, con límites ${ }^{49}$.

22. De este espectacular refuerzo a la optio iuris derivan consecuencias relativas a la dinámica del art. 83 a tener en cuenta de cara a la evaluación

42 Que, por lo demás, la propuesta de la Comisión no había contemplado siquiera separadamente: sí en cambio los pactos sucesorios.

43 Enmienda 121 al art. 50.

44 Enmienda 119.

45 Aparece ya en el Informe sobre la propuesta de Reglamento del Parlamento Europeo y del Consejo relativo a la competencia, la ley aplicable, el reconocimiento y la ejecución de las resoluciones y los actos auténticos en materia de sucesiones y a la creación de un certificado sucesorio europeo, A7-0045/2012, 6 de marzo de 2012, y con el número actual, en la Posición del Parlamento Europeo al respecto, EP-PE_TC1-COD(2009)0157, de 13 de marzo de 2012.

46 SchорPE, C., «Die Übergangsbestimmungen zur Rechtswahl im internationalen Erbrecht: Anwendungsprobleme und Gestaltungspotenzial», IPRax, 2014, pp. 27-33, esp. p. 29. En parecido sentido, Biagioni, G., «L'ambito di applicazione del regolamento sulle successioni», en FranzinA, P. y LEANDRO, A. (eds.), Il diritto internazionale privato europeo delle successioni mortis causa, Milán, Giuffrè, 2013 , pp. 25-58, esp. pp. 57-58, habla de un «efetto paradossale».

47 El caso del causante que otorga un testamento sin ningún tipo de consejo puede parecer (en principio) merecedor de mayor protección por esta ausencia, si bien también cabría defender que quien no recurre al asesoramiento en una materia tan compleja debería pechar con el riesgo de una invalidez.

48 El contraste con disposiciones transitorias en Reglamentos previos es puesto de manifiesto por Wautelet, P., loc. cit., nota 36, p. 963, nota al pie núm. 9, refiriéndose a los arts. 66.2 del Reglamento Bruselas I bis y al art. 64.2 del Bruselas II bis (aunque quizá los términos de la comparación no sean los mejores, por cuanto los preceptos aludidos por P. Wautelet contemplan el reconocimiento y ejecución de decisiones).

49 Alemania (art. 25.2 EGBGB), Italia (art. 46.2 Legge 218/95), Bélgica (art. 79 Code DIPr 2004),

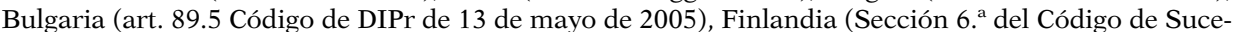
siones), Estonia (párr. 25 de la Ley de DIP de 27 de marzo de 2002), y Rumanía (art. 68.1 Ley DIPr de 22 de septiembre de 1992). La admitían igualmente los Países Bajos, por incorporación del Convenio de La Haya de 1989, según Ley de 4 de septiembre de 1996. 
de las Res. DGRN mencionadas en la Introducción: la autoridad nacional que hoy deba valorar la validez de un testamento otorgado antes del 17 de agosto de 2015 tendrá que empezar en todo caso buscando una eventual elección de ley expresa o tácita, aun cuando la misma hubiera sido impensable en aquel tiempo al amparo del DIPr aplicable (cuestión distinta es que el dato de cuál era ese régimen pueda ser orientativo sobre si ha habido elección; si en teoría no podrá ser tenido en cuenta porque no lo admite el art. $22^{50}$, lo cierto es que estamos en una situación excepcional, como todas las transitorias), y aun cuando el causante hubiera sido asesorado sobre el mismo (por ejemplo, el testamento fue uno abierto ante notario). Veremos a continuación si, no obstante, el apdo. 83.4 del Reglamento introduce algún matiz en esta dinámica.

\subsubsection{El art. 83.4}

23. El art. 83.4 del Reglamento resulta de una enmienda del Parlamento a la Propuesta de la Comisión, según la cual si una disposición testamentaria hubiera sido otorgada antes de la fecha de aplicación del Reglamento -incluido el periodo anterior a su entrada en vigor-, con arreglo a la legislación de un Estado que el causante habría podido elegir de conformidad con el art. 17 del presente Reglamento, tal ley se consideraría ley elegida ${ }^{51}$. No consta una explicación al texto: puede verse como preferencia conceptual por la elección de ley; como manifestación de la conciencia por parte del legislador europeo de que el punto de conexión previo al Reglamento, en muchos Estados miembros, era aún la nacionalidad; o como ambas cosas ${ }^{52}$. En relación con lo primero, la doctrina más autorizada ${ }^{53}$ presenta el texto como una disposición residual (catch-up clause) frente a las incertidumbres en relación con los criterios, a desarrollar en el marco de la interpretación autónoma del Reglamento, de lo que sea una elección tácita. Sobre lo segundo, la misma doctrina propone una lectura de la regla en clave de confianza y facilidad: el texto contempla casos en que un individuo, en un sistema presidido por el punto de conexión «nacionalidad» y sin posibilidad de elección, no consideró tal posibilidad e hizo testamento conforme a su ley nacional coincidente con la residencia habitual, ajeno a la idea de que un cambio de residencia habitual podría afectar a la validez del testamento - lo que efectivamente ocurre

50 Supra párrs. 8 y ss.

51 Enmienda 120, Proyecto de informe sobre la propuesta..., supra nota 40.

52 Lechner, K., loc. cit., nota 20, párrs. 11, 13; Franzina, P., "Art. 83», en Calvo Caravaca, A. L., Davì, A. y Mansel, H. (eds.), The EU Succession Regulation. A Commentary, CUP, 2016, pp. 853-863, párr. 17.

53 Lechner, K., loc. cit., nota 20, párr. 11. K. Lechner es autor del In-depth Study para el Parlamento Europeo «Verordnung (EU) Nr. 650/2012 über Erbsachen und die Einführung eines Europäischen Nachlasszeugnisses», 2015, y ponente en el Informe del Parlamento sobre la propuesta de Reglamento del Parlamento Europeo y del Consejo relativo a la competencia, la ley aplicable, el reconocimiento y la ejecución de las resoluciones y los actos auténticos en materia de sucesiones y a la creación de un certificado sucesorio europeo. 
tras el 17 de agosto de 2015-. Entender que la ley nacional ha sido elegida facilita la solución de estos casos en la práctica ${ }^{54}$.

24. A la luz de la explicación anterior cabe imaginar un rol para el art. 83.4 cuando una elección de ley no sea evidente (ya que en este caso entraría en juego el art. 83.2). En tal supuesto, especialmente si el punto de partida es el otorgamiento de la disposición mortis causa en un tiempo y bajo un ordenamiento donde elegir no fuera una opción posible, dar paso al art. 83.4 permite eliminar la necesidad de investigar tal elección, que pudo existir aun cuando el sistema original no la admitiera, y ser válida conforme a alguna de las opciones del art. 83.2. Esta manera de entender el precepto es, sin duda, de interés práctico en la perspectiva de una autoridad española ante la que se sustancie una sucesión cuando exista (como en las resoluciones de la DGRN que dan origen a estas reflexiones) un testamento otorgado en España.

\subsection{Interpretación del texto}

25. Existen dudas sobre la interpretación del texto: unas afectan a varios o todos sus apartados a un tiempo, otras son singulares ${ }^{55}$.

\subsubsection{Con carácter general}

26. El art. 83 utiliza conceptos que aparecen en otros lugares del Reglamento: elección de ley, disposición mortis causa, admisibilidad y validez, residencia habitual... En principio no hay razón para suponer que su definición es diferente: piénsese que en otro caso el ámbito de aplicación del precepto podría no coincidir con el general del Reglamento. Al mismo tiempo, atendiendo a la función particular de la norma - Derecho inter-temporal-, podría sostenerse una opinión distinta: por ejemplo, que da cabida a cualquier mecanismo en el cual el causante hubiera depositado expectativas de organización de su sucesión, y cuya calificación como disposición mortis causa esté aceptada en un determinado Estado miembro, aun cuando existan dudas sobre la misma desde la perspectiva del Reglamento ${ }^{56}$ - e incluso si finalmente una interpretación autónoma del texto condujera a excluirla de su ámbito de

54 LECHNER, K., loc. cit., nota 20, párr. 13.

55 Las observaciones que haremos sobre el art. 83 giran en torno a la elección de ley y las disposiciones mortis causa distinta de los pactos sucesorios; estos últimos requieren desarrollos específicos que no vamos a abordar.

56 Existen dudas sobre la calificación en relación con liberalidades como la donación mortis cau$s a$, que solo algunos ordenamientos someten a las normas de la sucesión: véase Bonomi, A., loc. cit., nota 12, párr. 51. Otros ejemplos de difícil calificación son los will-substitutes del Derecho anglosajón, modalidades de transmisión al margen de la sucesión pero que participan de rasgos comunes a las disposiciones de última voluntad (id., párr. 41); o los pactos sucesorios de disposición (id., "Art. 3», párr. 20). 
aplicación- ${ }^{57}$, si como resultado de esa inclusión tal disposición es válida (y no lo sería de otro modo). En parecido sentido y por el mismo motivo, la definición de «residencia habitual» que da paso a la ley del Estado de la misma como alternativa al Capítulo III en el art. 83.2 y 83.3 podría no ser la del Reglamento, sino la vigente conforme a tal ordenamiento ${ }^{58}$.

27. En la medida en que el art. 83 incorpore las nociones en uso en el resto del texto traerá con ellas sus dudas. Un ejemplo: la discusión en el marco del art. 24 a propósito de la distinción, que opera en algunos ordenamientos, entre la disposición por causa de muerte en sentido formal (o «acto de disposición»: el testamento, el testamento mancomunado o el pacto sucesorio) y en sentido material (a la que también se alude como "modo de disponer», y que designa la institución de heredero, los legados, sustituciones, o el nombramiento de un ejecutor testamentario $)^{59}$. La pregunta sobre si las reglas especiales del art. 24 engloban la admisibilidad y validez en cuanto al fondo de ambos tipos de disposición se proyecta también sobre el art. 83.

28. La aplicabilidad del art. 83 en el tiempo ha generado igualmente discusión. Por lo que se refiere a la validez de una elección de ley reguladora bien de la sucesión al completo, bien de una disposición mortis causa, se ha preguntado la doctrina si se contemplan las realizadas también antes de la entrada en vigor del texto el 16 de agosto de 2012, incluso para ser valoradas conforme al Capítulo III del Reglamento. Prevalecen las opiniones favorables; y ello es, como hemos visto en el apartado previo, lo que parece derivarse de la evolución en las negociaciones del texto ${ }^{60}$. La ausencia de límites temporales permite extender el Reglamento por igual a un testamento otorgado en 2003 y a otro en $2014^{61}$ si el causante fallece tras el 17 de agosto de 2015, a pesar de que la situación de partida era evidentemente distinta desde el punto de vista legal.

29. Se discute también cuáles son los sistemas de DIPr que el precepto considera como alternativas posibles al Capítulo III del Reglamento a la hora de apreciar la validez (en su caso, también la admisibilidad) de una elección de ley, o de una disposición mortis causa: si solo los de los Estados miembros o también los de Estados terceros. Parte de la doctrina se pronuncia a favor de lo primero con apoyo en uno de los objetivos del precepto, cual es el de facilitar

57 El Reglamento no consagra el recurso necesario a la interpretación autónoma, excepto en lo relativo a la autenticidad del documento público (cdo. 62).

58 Otra opinión BaueR, F., «Art. 83», en DutTA, A., Internationales Erbrecht, Munich, C. H. Beck, 2016, párr. 12 .

59 Se refiere a ella Bonomi, A., «Art. 3», párr. 10; «Art. 24», párr. 6, y «Art. 25», párr. 15, en BonoMI, A. y Wautelet, P., Le droit européen des successions, Bruselas, Bruylant, 2016, si bien para rechazar que haya sido acogida en el Reglamento.

60 Véase no obstante DöRner, H., loc. cit., nota 13, para quien la elección contemplada es la posterior a la entrada en vigor del texto. En España le sigue CARRAScosa González, J., op. cit., nota 14, párr. 52. En contra, WAUTELET, P., loc. cit., nota 36, nota al pie núm. 15, con más referencias en este sentido; Rosoux, H., "Arrêt sur le régime transitoire du Règlement successions», Revue de planification patrimoniale belge et internationale, 2014, párr. 1, nota al pie núm. 8; FongARO, E., «L'anticipation successorale à l'épreuve du règlement successions», JDI, abril de 2014, versión en línea, p. 26.

61 Como ocurre en las resoluciones aludidas en la nota al pie núm. 1. 
la transición entre los regímenes; algo en lo que no se tiene en cuenta a los Estados terceros, a los que el Reglamento no vincula ${ }^{62}$. En contra se posicionan otros autores, argumentando que el propósito general de la regla es evitar que la introducción del nuevo régimen frustre las expectativas del de cujus, conservando la validez de los actos realizados antes de ella, y no facilitar una transición fluida entre regímenes a quienes han de aplicarlos ${ }^{63}$; se indica también que la distinción entre Estados miembros y terceros iría en contra de la regla de aplicación universal que sienta el art. $20^{64}$. En todo caso, los primeros autores tienen razón en lo relativo a la alternativa «ley de la autoridad que sustancie la sucesión», solo presente en el art. 83.3: aunque no por los motivos que alegan, sino por el hecho obvio de que las únicas autoridades a las que el Reglamentos se refiere en tanto que encargadas de la sucesión son las de Estado miembro (de hecho, el propio texto alude aquí a «Estado miembro de la autoridad»).

30. La última pregunta de carácter general que suscita la aplicación del art. 83 es la relativa a cómo se reconstruye el régimen jurídico de una sucesión para la que el de cujus realizó actos de planificación antes del 17 de agosto de 2015, pero no conforme al Capítulo III del Reglamento sino a alguna de las otras posibilidades: el DIPr del Estado de su residencia habitual, de su nacionalidad, o (caso del art. 83.3) de la autoridad ante la que se sustancia la sucesión. La necesidad de reconstrucción puede deberse a distintas circunstancias. En el marco del art. 83.3, según su propio tenor las normas de DIPr nacionales intervienen solo en relación con la admisibilidad y validez formal y material de una disposición por causa de muerte; este es el ámbito material de la ley sucesoria anticipada, por lo que será preciso identificar la ley que concurre con ella para regular el resto de los aspectos de la sucesión. En el caso de una elección de ley conforme al art. 83.2, ocurre que por una parte el texto solo contempla la validez — si bien luego veremos las dudas sobre la realidad de este límite- ${ }^{65}$. Por otra, es perfectamente posible imaginar una elección cuyo alcance está restringido de entrada: así, porque conforme al DIPr aplicable las legítimas se regulan necesariamente por un ordenamiento diferente $^{66}$. A nuestro juicio, la identificación de la ley «complementaria» debe

62 Wautelet, P., loc. cit., nota 36, párr. 18, seguido por Rosoux, H., loc. cit., nota 60, en su nota al pie núm. 40.

63 Franzina, P., loc. cit., nota 52, párr. 12. También DutTA, A., «Art. 83», Münchener Kommentar, Band 10 (Internationales Privaterecht I), 2015, párr. 7; Fongaro, E., loc. cit., nota 60, p. 26; en España, Iglesias Buhigues, J. L., "Art. 83», en Iglesias Buhigues, J. L. y Palao Moreno, G., Sucesiones internacionales, Tirant lo Blanch, 2015, pp. 668-675, esp. p. 672. También, aunque sin mayor explicación, FERNÁNDEZ-TrEsguerres García, A., Las sucesiones mortis causa en Europa: aplicación del Reglamento (UE) núm. 650/2012, Aranzadi, 2016, p. 773.

${ }^{64}$ BAUER, F., loc. cit., nota 58, párr. 15.

65 En el apartado que sigue abordamos la cuestión de si el punto de partida —elección de ley que no respeta la unidad de la sucesión- es aceptable en el marco del Reglamento, o si por el contrario toda elección que sea válida por virtud de una de las opciones del art. 83.2 pasa necesariamente a regir el conjunto de los bienes, y la totalidad de la sucesión en el sentido del art. 23, con lo cual el problema que evocamos en el texto no se plantearía.

${ }^{66}$ Véase el art. 79 Code DIPr belga: «Une personne peut soumettre l'ensemble de sa succession au droit d'un Etat déterminé. La désignation ne prend effet que si cette personne possédait la nationalité de cet Etat ou avait sa résidence habituelle sur le territoire de cet Etat au moment de la désignation ou du 
producirse conforme al Reglamento incluso cuando la validez de la elección o de la disposición por causa de muerte resulte de uno de los sistemas nacionales de DIPr que contempla el art. 83, y no del Capítulo III del instrumento europeo; será, en definitiva, la ley de la residencia habitual o la que presente vínculos más estrechos (art. 21), acompañada por las reglas de aplicación del Reglamento (arts. 34, 35, etc). Otra solución cambiaría completamente la regla de aplicación temporal por la que ha optado el legislador europeo y, por tanto, debería haber encontrado expresión en el texto: por ejemplo, en una norma que indicara sin más que el Reglamento no se aplica a las sucesiones de quienes hubieran realizado una elección de ley o una disposición mortis causa válidas antes de su entrada en vigor, aun cuando el fallecimiento ocurriera el o después del 17 de agosto de 2015. Cuestión distinta es el "perímetro» de la ley de la residencia habitual/conexión más estrecha del art. 21, que será variable en el caso de una elección de ley parcial ${ }^{67}$.

\subsubsection{Aspectos singulares}

\section{a) El art. 83.2}

31. Sobre el art. 83.2 existe en primer término la duda acerca de qué elección de ley es la que contempla: en otras palabras, si tiene cabida cualquiera, incluyendo la limitada a una parte de la herencia (en cuanto a bienes) o a aspectos de la misma (por ejemplo, la admisibilidad o/y validez de una disposición por causa de muerte). A nuestro juicio, como ya sugeríamos en el apartado previo, debe responderse a esto en sentido afirmativo. No sería lógico establecer una limitación a priori; la opción del causante puede haberse expresado en una forma o con un alcance tal que no sería considerada elección de ley (más bien: elección de ley admisible y válida) a la luz del Reglamento, pero sí de uno o varios de los sistemas de DIPr que el precepto contempla como opciones. Algún autor expresa no obstante otra opinión, excluyendo del art. 83.2 una elección del estilo de la prevista en el art. 24.2 Reglamento; la misma "fallt unter die Sonderregel des Abs. $3{ }^{68}$. La consecuencia de esta interpretación es que la validez una elección de ley limitada a la admisibilidad y validez formal y de fondo de una disposición por causa de muerte no se beneficia de las alternativas del art. 83.269.

décès. Toutefois, cette désignation ne peut avoir pour résultat de priver un héritier d'un droit à la réserve que lui assure le droit applicable en vertu de l'article 78». El precepto ha sido derogado por la Ley de 6 de julio de 2017, Loi portant simplification, harmonisation, informatisation et modernisation de dispositions de droit civil et de procédure civile ainsi que du notariat, et portant diverses mesures en matière de justice, pero mantiene su aplicabilidad en virtud del art. 83 del Reglamento a los casos que este mismo determina.

${ }^{67}$ Siempre y cuando no se entienda que la elección, válida conforme a un sistema distinto del Reglamento, pasa necesariamente a regir la totalidad de la sucesión con independencia de lo que pueda determinar al respecto el sistema de DIPr de partida, o la voluntad del difunto. Supra nota 65.

68 DutTA, A., loc. cit., nota 63, párr. 7.

69 Wautelet, P., loc. cit., nota 36, párr. 9. 
32. De gran trascendencia práctica es la cuestión de los efectos o consecuencias normativas de una elección de ley previa al 17 de agosto de 2015, que no es válida conforme al Capítulo III del Reglamento, pero sí a tenor del DIPr de uno de los Estados que el art. 83.2 enumera. En este sentido hay que recordar que una elección tan amplia en su alcance como la que consagra el Reglamento no era habitual antes del mismo. Bélgica y Alemania proporcionan ejemplos característicos de elecciones limitadas: el Code de DIPr belga permitía la elección de la ley de la residencia habitual en el momento de la elección, pero siempre protegiendo las legítimas ${ }^{70}$; el art. 25 EGBGB alemana excepcionaba la regla general —aplicación de la ley nacional del causante al tiempo del fallecimiento- con la posibilidad de elegir la ley alemana para la sucesión en la propiedad inmobiliaria, siendo Alemania el lugar de situación de tales bienes ${ }^{71}$.

33. Literalmente, el art. 83.2 solo salva la validez de la optio iuris del causante: si nos atenemos a la letra del precepto los sistemas de DIPr alternativos al Capítulo III del Reglamento no tienen otro alcance. La consecuencia es que el efecto de una elección válida vendrá determinado por el Reglamento mismo; la ley elegida se aplicará, como regla, a toda la sucesión, como ocurre en el caso de optio iuris el o tras el 17 de agosto de $2015^{72}$. La solución es descrita en la doctrina como una especie de dépéçage: la profesio iuris se conserva a la luz de una regla de DIPr nacional, pero sin que la misma sea aplicada en su totalidad ${ }^{73}$. En nuestra opinión resulta extraño aceptar que una professio iuris es válida, mas separarla del ámbito de operatividad previsto para ella por el sistema que la ampara. El resultado es peculiar: al mantener una elección sin respetar su alcance lo que se defiende es el hecho de elegir, conceptualmente (el si), y no en su proyección a cada caso concreto (el para qué o sobre qué se aplica lo elegido). La solución es difícil de aceptar desde el propio Reglamento: a diferencia de sistemas como el alemán, donde la professio iuris se introdujo para "faciliter la tâche des autorités allemandes lorsque la succession d'un étranger —en principe soumise à sa loi nationalecomprend des immeubles en Allemagne» ${ }^{74}$, en el Reglamento la finalidad es la de asegurar la previsibilidad y la estabilidad del régimen sucesorio, evitando las incertidumbres ligadas a la concreción de un punto de conexión mutable

70 Supra nota 66.

71 "(1) Die Rechtsnachfolge von Todes wegen unterliegt dem Recht des Staates, dem der Erblasser im Zeitpunkt seines Todes angehörte. (2) Der Erblasser kann für im Inland belegenes unbewegliches Vermögen in der Form einer Verfügung von Todes wegen deutsches Recht wählen».

72 El art. 22 del Reglamento no tolera una elección de ley parcial, de manera que la misma será inválida si no cabe interpretar la voluntad del causante como elección global. Una elección de ley limitada es posible no obstante para la admisibilidad y validez material de la disposición mortis causa (art. 24.2), y de los efectos vinculantes, en el caso del pacto sucesorio (art. 25.2).

73 WaUtelet, P., loc. cit., nota 36, párr. 20.

74 Como explica Bonomi, A., Successions internationales. Conflits de lois et de juridictions, Rec. des Cours, vol. 350, 2011, p. 204. Y sigue: "Grâce à elle, la procédure de délivrance d'un certificat d'héritier, nécessaire pour l'inscription des héritiers au registre foncier allemand (Grundbuch), peut se dérouler plus simplement et rapidement, car elle se base alors sur le droit interne». También KoHLER, C., loc. cit., nota 12, párr. 129. 
(in casu, de la residencia habitual). Si esta filosofía se lleva al art. 83, lo razonable es respetar toda la previsión del causante que realizó la elección, y organizó el destino de sus bienes a la luz del ordenamiento elegido en el marco de la extensión permitida por él ${ }^{75}$.

34. Es interesante además recordar que el Reglamento solo permite la elección de la ley nacional del causante, y que tal limitación se explica, conforme al cdo. 38, en la pretensión de proteger las expectativas de los herederos legitimarios. En los ordenamientos que admiten la professio iuris esta ha sido también la razón que en general ha motivado las restricciones a la posibilidad de elegir, articuladas, no (o no solo) en forma de límite en cuanto a qué ordenamientos pueden ser objeto de elección, sino también en cuanto a su alcance material (véase el art. 79 Code DIPr belga). A nuestro juicio, parece lógico que si la filosofía de la restricción es la misma también sus concreciones se respeten en el paso del antiguo régimen al del Reglamento. Algo similar puede predicarse en relación con los sistemas en que la elección se limita a los bienes inmuebles por motivos ajenos a la anticipación sucesoria, y ligados a la relación entre la sucesión y los derechos reales: el ejemplo típico, como vimos, era el art. 25 EGBGB. Al fin y al cabo el Reglamento tolera que ciertos bienes o empresas conserven su régimen particular; parece razonable sostener que tras el Reglamento la elección de una ley en las condiciones descritas (ley alemana, lex rei sitae, para los bienes inmuebles en tal país) mantenga su efecto limitado a esos bienes, porque la idea de prever para ellos un tratamiento especial no es ajena al sistema vigente - aun cuando el argumento de fondo que lo justifica no sea del todo coincidente- ${ }^{76}$.

35. Finalmente, no se cuestiona que una elección más generosa que la del Reglamento mantenga todos sus efectos tras la entrada en vigor de este, al amparo del art. $83^{77}$. En nuestra opinión, si esto es así, lo mismo debe valer para el caso opuesto. Sin duda las consecuencias para la práctica pueden resultar complejas: sostener que la elección válida conforme a un sistema distinto del Reglamento - aunque tolerado por este- posee el alcance que prevea dicho sistema significa que si es limitado (a ciertos bienes, a ciertos aspectos de la sucesión) habrá que recurrir a una ley complementaria que, como vimos en el apartado precedente, no será ya la prevista en el aquel sistema, sino la de la residencia habitual del causante (excepcionalmente una con vinculación manifiestamente más estrecha, art. 21 del Reglamento).

75 Lo habitual no será la elección de ley para una sucesión intestada, sino testada. Pero incluso en el primero de los casos hay que insistir en que si bien la professio iuris en materia sucesoria tiene una dimensión localizadora, lo más relevante es que a través de ella el causante organiza el reparto de su patrimonio para después de su muerte. En este sentido no es una solución flexibilizadora de la norma de conflicto, sino material.

76 BAUER, F., loc. cit., nota 58, párr. 20, sigue este razonamiento para concluir que una elección limitada a ciertos bienes de la sucesión (el ejemplo alemán) solo debe regir esa parte de la sucesión. Su opinión es la opuesta en cambio para el caso de la elección restringida a aspectos de la sucesión (caso belga), y se justifica a la luz de los supuestos de dépeçage que el Reglamento mismo admite (arts. 24.2, 25.2).

77 Wautelet, P., loc. cit., nota 36, párr. 21. 
36. En todo caso, lo correcto es reconocer que a día de hoy la cuestión no está resuelta; su dificultad se refleja en la marcada división de opiniones de la doctrina. Autores como Kurt Lechner, Christoph Schoppe, o Pietro Franzina ${ }^{78}$ defienden mantener los efectos que la professio iuris tenía en el sistema de DIPr nacional, y ello aunque la consecuencia sea la ruptura de la sucesión en términos de ley aplicable: si ello atenta contra una de las ideas fuerza del Reglamento, cual es el principio de unidad de la sucesión, es cierto también que el propio Reglamento admite inflexiones a tal principio. Estos autores no siempre explican su postura. Cuando lo hacen el razonamiento suele ser el de salvaguardar las expectativas del causante frente a la aplicación sobrevenida de un régimen distinto al vigente al realizar la elección; no hay razones para asociar a la misma más efectos que los previstos por el ordenamiento nacional ${ }^{79}$.

37. Otros autores optan más o menos claramente ${ }^{80}$ por la solución opuesta: "Die Folgen einer nach Abs. 2 wirksamen Rechtswahl, insbesondere ihr Umfang, richten sich am oder nach dem Stichtag nach Art. 22 der Verordnung und [...] nicht nach dem nationalen Kollisionsrecht» ${ }^{81}$. Refiriéndose a la elección tácita, pero en unos términos que son igualmente válidos para la expresa, se ha dicho que: «El principio de unidad que inspira el reglamento se proyecta [...] hacia el pasado: la ley tácitamente elegida se aplica a la totalidad de la sucesión, y no únicamente a las disposiciones de las que se dedujere, independiente de cuál fuere la posición del DIPr del foro en el momento de la elección» ${ }^{82}$. A favor de adoptar los efectos del propio Reglamento se argumentan ante todo el principio de unidad de la sucesión, pero también la falta de criterio para decidir entre las opciones que ofrece el art. 83 cuando la elección de ley sea válida conforme a más de una de ellas ${ }^{83}$. A esto han respondido otros autores al amparo de una regla general en materia de elección de ley: si varias de las alternativas permitieran considerar la disposición como válida habría que aplicar aquella "qui le fait dans la plus grande mesure»; ello, "under a teleological interpretation of art. 83.2» ${ }^{84}$.

38. A la vista de las dudas expuestas es de lamentar una redacción más clara del texto. Los trabajos preparatorios no aportan claves. El Convenio de

78 Lechner, K., loc. cit., nota 20, párr. 37; Schoppe, C., loc. cit., nota 46, p. 31; Franzina, P., loc. cit., nota 55, párr. 9: "For the purposes of article 83.2, validity should be understood in broad terms as encompassing admissibility, formal validity, effectiveness and enforceability».

79 Franzina, P., loc. cit., nota 52, párr. 10.

80 Dubitativo Wautelet, P., loc. cit., nota 36, párr. 20.

81 DutTa, A., loc. cit., nota 63, párr. 7; con los matices indicados en nota 76, BaUer, F., loc. últ. cit.

82 GonzÁlez BeIlfuss, C., «El ámbito de aplicación del Reglamento de sucesiones», en GineBRA Molíns, M. E. y Tarabal Bosch, J., pp. 55-77, párr. 8 (cursiva añadida). Carrascosa GonzÁlez, J., op. cit., nota 14, p. 125; y entre la doctrina extranjera, además de la citada en las notas precedentes Pamboukis, H., «Art. 83», en Pamboukis (ed.), EU Succession Regulation, núm. 650/2012, C. H. Beck, Hart, Nomos, 2017, párr. 10.

83 DutTA, A., loc. cit., nota 63, párr. 7 in fine.

84 Rosoux, H., loc. cit., nota 60, párr. 17, FrANZINA, P., loc. cit., nota 52, para 11. Se aprecia cierta contradicción en el último autor: bajo el para. 10 ha excluido los mayores efectos que pudiera otorgar el Reglamento «in the light of the goal pursued by art. 83.2», y lo ha identificado con la protección de las expectativas del causante. Pues bien, estas no tienen por qué ser las de la elección más liberal en cuanto a su extensión. 
La Haya de 1989 no parece haber funcionado aquí como modelo ${ }^{85}$. Tampoco cabe extraer una conclusión segura con apoyo en el argumento sistemático: el art. 83.3 solo contempla la admisibilidad y validez de la disposición mortis causa, excluyendo los efectos de la misma ${ }^{86}$, pero el paralelismo entre este párrafo y el segundo es limitado. Los términos del problema no son los mismos: el ejercicio de la autonomía de la voluntad material carece del potencial normativo de una elección de ley; si el causante procede, no solo a elegir la ley aplicable, sino también a organizar su sucesión conforme al ordenamiento elegido, tal potencial empieza a manifestarse a partir del momento en que se produce la elección, sin esperar al momento de la muerte. Tampoco ayuda el art. 83.4, donde se establece una ficción de elección de ley, y (según la opinión general ${ }^{87}$ se atribuye la regulación del conjunto de la sucesión a la ley «elegida». Hemos señalado ya que el texto tiene una justificación propia, que hace difícil extrapolar del mismo cualquier conclusión a los efectos aquí discutidos. Por otra parte, la ficción se produce en relación con la ley que podría haberse elegido conforme al Reglamento tras el 17 de agosto de 2015: elección que, de haber sucedido, habría tenido en todo caso alcance global, por virtud del art. 22.

\section{b) Sobre el art. 83.3}

39. Hemos aludido más atrás a los posibles problemas de interpretación que presenta el art. 83.3 en tanto que incorpora nociones que aparecen en otros lugares del Reglamento. Igualmente hemos señalado que la referencia a la «admisibilidad y validez formal y material» trae a la disposición el esquema de reparto o fraccionamiento entre los ordenamientos concurrentes (ley sucesoria, ley sucesoria anticipada) establecido por el propio Reglamento ${ }^{88}$. La alternatividad de los sistemas - el Capítulo III del Reglamento y los otros sistemas de DIPr - se proyecta solo sobre que se indica en el texto, es decir, la validez formal y material de la disposición, y no sobre los efectos de la misma. Esto es coherente con la idea que inspira el art. 24 del Reglamento: "La costatazione che $i$ testamenti producono effetti solo a partire dalla morte del loro autore ha opportunamente condotto a espungere dall'art. 24 reg. ogni riferimento alla disciplina degli effetti di tali negozi» ${ }^{89}$.

85 Indicaba el art. 5.4 que: «A los efectos del presente artículo se considerará que, a falta de disposición expresa en contrario del difunto, la designación de la ley aplicable afecta a la totalidad de la sucesión, tanto si el difunto hubiera fallecido intestado como si hubiera dispuesto por testamento de la totalidad o de una parte de sus bienes». A la luz del informe, Donovan, W. y WATERs, M., loc. cit., nota 37, p. 558, el precepto sirve a reforzar la regla en casos de elección en los que realizada la misma la sucesión es intestada, o en parte testada y en parte intestada.

${ }_{86}$ Remitimos al apartado siguiente para un análisis con mayor profundidad sobre este aspecto.

87 Si bien es cierto que el art. 83.4 no indica que ese sea el alcance de la ley nacional, esa es la comprensión más extendida: véase infra, bajo $c$ ).

88 Se reproduce así el ámbito del art. 24; la validez formal se encuentra en realidad regulada en el art. 26, también en el Capítulo III. El art. 25, relativo a los pactos sucesorios, también menciona los efectos vinculantes entre las partes, cosa que no hace el art. 83.3, generando dudas doctrinales que no reproducimos, en línea con la opción anunciada de dejar al margen estos actos.

89 Damascelli, D., Diritto internazionale private delle successioni a causa di morte, Giuffrè, 2013, pp. 98-99. 
40. Queda por abordar algún extremo. En primer lugar, la diferencia entre los arts. 83.2 y 83.3 en cuanto al número de alternativas que ofrecen: la ley de la autoridad ante la que se sustancie la sucesión solo aparece en el apdo. 3. No parece existir ninguna razón para ello: no responde al hecho de que la elección de ley tenga una lógica propia (la que hemos evocado en el apartado previo) en comparación con una disposición mortis causa. Tampoco cabe argumentar que asegurar la coincidencia fórum-ius, que es el resultado en definitiva de la opción «Estado miembro de la autoridad que sustancie la sucesión», sea un objetivo de mayor importancia cuando hay una disposición mortis causa que frente a una elección de ley. La doctrina ha criticado la diferencia, que califica de inexplicable ${ }^{90}$.

41. Finalmente, a propósito de la relación entre los apdos. 2 y 3 del art. 83, parece justificado entender que si la disposición por causa de muerte contiene al tiempo una elección de ley y disposiciones sustantivas se aplicarán respectivamente los apdos. 2 y 3 del art. 83 del Reglamento ${ }^{91}$. Si la elección de ley es válida concurrirá con el resto de las previstas en el art. 83.3 a fin de determinar la validez de la o las disposición mortis causa.

\section{c) Sobre el art. 83.4}

42. La sencillez del último apartado del art. 83 es solo aparente; el precepto suscita críticas e interrogantes: sobre el alcance de la ley nacional; y sobre el funcionamiento del texto. Tampoco su relación con los apartados previos se entiende siempre igual, como prueban las diferentes sistemáticas seguidas por los autores al abordar el precepto: después del art. 83.2, resaltando su parentesco con la elección de ley; o tras el art. 83.3, reflejando la identidad del supuesto de hecho de ambos párrafos ${ }^{92}$.

43. Dado que todavía hay autores que formulan la cuestión ${ }^{93}$, o incluso defienden lo contrario ${ }^{94}$, merece una breve mención el hecho de que conforme a la opinión mayoritaria el art. 83.4 sienta una ficción, y no una presunción iuris tantum ${ }^{95}$.

90 Franzina, P., loc. cit., nota 52, párr. 11.

91 Rosoux, H., loc. cit., nota 60, párr. 12; WAUTELET, P., loc. cit., nota 36, párr. 9. Supra nota 68, en cambio, la opinión de A. DuTTA.

92 Para lo primero DutTa, A., loc. cit., nota 63, párr. 8, o Fernández-Tresguerres García, A., op. cit., nota 64, p. 773; para lo segundo, que es más común, véase, por ejemplo, WAUTELET, P., loc. cit., nota 36 , párr. 20 , párrs. 28 y ss.

93 Godechot, S., «Le nouveau droit international privé des successions: entre satisfactions et craintes...», Recueil Dalloz, 2012, p. 2462, párr. 37.

94 A favor, Biagioni, G., loc. cit., nota 46, p. 58; Goré, M., loc. cit., nota 14, párr. 10. En España parece ser la interpretación, además de RIPOLl Soler, A., loc. últ. cit., nota 17, de Fernández-TresGUERRES GARcía, A., op. cit., nota 64, p. 773.

95 Claramente Lechner, K., loc. cit., nota 20, párrs. 10 y ss.; Rosoux, H., loc. cit., nota 60, párr. 18, como WaUtelet, P., loc. cit., nota 36, párr. 32. DutTA, A., loc. cit., nota 63, párr. 8 in fine, pese a entender lo mismo, lo lamenta. Es errónea a nuestro juicio la descripción de RIPOLL Soler, A., loc. cit., nota 17, bajo 4.2, que lo califica de «ejemplo legislado de elección de ley realizada tácitamente». 
44. A propósito del ámbito de la ley nacional, es común la opinión de que es aplicable a toda la sucesión, sin que ello elimine las críticas al respecto ${ }^{96}$. Sin duda es llamativo derivar la aplicación a la totalidad de la sucesión de la ley nacional del causante por el solo hecho de que una disposición singular se haya redactado conforme a ella ${ }^{97}$. Es obligado preguntarse además sobre qué hacer cuando existan varias disposiciones por causa de muerte, si la consecuencia de proyectar la ley nacional sobre el conjunto es negar la validez de alguna de ellas. Una solución posible es que el art. 83.4 no se aplica, sin más, en este caso.

45. Sobre cómo interpretar la exigencia de que la disposición en juego «se realizara con arreglo a la ley», a la vista de los principios que lo inspiran la doctrina sugiere una interpretación generosa, admitiendo que son suficientes indicios menores ${ }^{98}$. La pregunta es si cabría ir más lejos y sostener que la simple validez de la disposición mortis causa a la luz de la ley nacional otorga ya la preferencia a esta, o si es preciso en todo caso que el causante se acomodara a dicha ley con la conciencia de hacerlo. En nuestra opinión prevalece lo primero - siempre que ello no vaya contra una elección clara de ley, que en el marco del art. 83 puede no ser a favor de la ley nacional-. Tal solución debe imponerse al menos cuando el supuesto bajo examen coincida con el que justifica esta disposición, cuyo punto de partida son sistemas nacionales de DIPr en los que solo se permitía disponer mortis causa conforme a la ley nacional, y no la elección de ley no era posible; a la luz de este dato es legítimo abstenerse de indagar cuál era la voluntad del causante en el caso concreto ${ }^{99}$.

46. Por lo que respecta a la relación con el art. 83.3, la pregunta es si el art. 83.4 sienta la primacía de la ley nacional sobre las otras posibilidades contempladas por aquel precepto: de ser así, existiendo una disposición mortis causa el análisis de su admisibilidad y validez debería siempre comenzar por dicha ley, y pasar solo a las otras ante un resultado negativo de tal análisis. A nuestro juicio cabe defender que sí: la vocación de la ley nacional de regir toda la sucesión parece conferirle una posición preferente sobre las demás, que se traduce en el orden en que el operador jurídico consultará las distintas leyes.

47. A la luz de los supuestos de hecho de los apdos. 2 y 4 del art. 83 cabría concluir en principio que los mismos no «se tocan»: si el punto de partida en el art. 83.2 es una elección de ley, en el apdo. 4, justamente, no la

96 DutTA, A., loc. últ. cit.

97 Biagioni, G., loc. cit., nota 46, p. 58. En la misma línea, Goré, M., loc. últ. cit., ejemplificando con el caso del americano que reside en Francia y que redacta una disposición por causa de muerte por la que constituye un trust relativo solo a ciertos bienes.

98 LECHNER, K., loc. cit., nota 20, párrs. 12, 14.

99 DutTa, A., loc. cit., nota 63, párr. 8, sostiene otra cosa. Es de la misma opinión que la expresada en el texto Wautelet, P., loc. cit., nota 36, párr. 32. Probablemente también Franzina, P., loc. cit., nota 52, párr. 21: "The presumption in question is not meant to unveil the actual intentions of the de cujus as regards the law applicable to his or her succession. Rather, it is intended to restore the conditions for the substantive planning of the latter to be enforced». 
hay. Ello no significa, sin embargo, que no haya situaciones en que ambos apartados puedan concurrir: así, si hay una elección de ley (no coincidente con la ley nacional), pero también una disposición mortis causa que sería válida conforme a la ley nacional. El favor del Reglamento a la planificación sucesoria y la elección de ley conducen a pensar que en tal caso el art. 83.4 no entrará en juego. Como mucho, si en tal caso la disposición mortis causa fuera inválida conforme a la ley elegida pero válida según la ley nacional, cabría aún conservarla: pero no sustituir con la ley nacional el ordenamiento elegido para el resto.

\section{LAS RESOLUCIONES DE LA DGRN}

\subsection{Los supuestos}

48. Las resoluciones de la DGRN objeto de comentario ${ }^{100}$ tienen un punto de partida casi idéntico: el causante, nacional extranjero con última residencia en España, otorgó testamento aquí antes del 17 de agosto de 2015, pero falleció después; teniendo hijos, nombró heredera universal a otra persona. Se incluye en los testamentos objeto de examen en 2016 y 2017 una cláusula que deja a salvo los posibles derechos que la ley de la nacionalidad al tiempo del fallecimiento (en la Resolución de 2017: «La ley que regule la sucesión») otorgue a los legitimarios. Ignoramos si constaba también en la Resolución de 2018.

49. Son elementos diferenciales: la nacionalidad del causante (británico en las de 15 de junio, 4 de julio de 2016 y 2 de marzo de 2018, y alemán en la de 10 de abril de 2017); la fecha de otorgamiento del testamento (con anterioridad a la entrada en vigor del Reglamento en las dos primeras; en el periodo interino entre la entrada en vigor y la fecha de aplicación en la tercera) ${ }^{101}$. Hay bienes fuera de España sin duda en el caso que origina la Resolución de 10 de abril de 2017; no los hay en la de 4 de julio de 2016, y existen dudas al respecto en la que queda.

50. Las Resoluciones de 2016 y 2017 resuelven recursos elevados contra la nota de calificación del encargado del registro de la propiedad, que suspende la práctica de la inscripción solicitada por motivos ligados a su convicción acerca de la ley aplicable al amparo del Reglamento ${ }^{102}$ : la española, en las Resoluciones de 2016, como ley de la última residencia habitual del causante

\footnotetext{
100 Supra nota 1.

101 El testamento no solo se redactó tras la fecha de publicación, como indica la registradora, sino bajo la vigencia actual del mismo.

102 En la RDGRN de 15 de junio de 2016, así como en la de 4 de julio, la registradora sostenía la necesidad de que todos los herederos forzosos intervinieran en la partición de la herencia, porque así lo exige el Código Civil español. En la de 10 de abril, el problema esencial es la falta de prueba del Derecho extranjero. En la de 2018 el registrador exigía la presentación de resolución judicial inglesa expedida por el Probate Service.
} 
—la DGRN concluirá que se aplica la extranjera, elegida por él—; y la alemana, en la de 2017, justamente como resultado de atender al precedente sentado por la DGRN a través de las otras dos -la DGRN concluirá que se aplica la española de la residencia habitual—, rechazando que haya habido elección. En la Resolución de 2018 registrador y notario coincidían en cambio en cuanto a la ley aplicable - la inglesa, en todo caso-, y discrepaban sobre la norma de conflicto - la DGRN, por su parte, retomó los razonamientos empleados en la de 4 de julio de 2016-.

\subsection{Sobre la ley aplicable}

\subsubsection{La ley aplicable en las Resoluciones de 2016 y 2018}

51. La Resolución de julio de 2016 sigue a la de junio a la hora de identificar la ley aplicable. En esta, la DGRN comienza evocando el art. 83 y procede en primer lugar a buscar una posible elección (FD 4), que de existir primaría sobre la ley de la residencia habitual (FD 5). No hay nada que objetar al planteamiento hasta este punto: como indicamos más atrás, el art. 83, apdos. 2 y 3, lleva al extremo el favor por la planificación sucesoria que es eje del Reglamento, hasta el punto de obligar a investigar si hubo elección de ley incluso donde el punto de partida (esto es, el DIPr en el lugar y momento del otorgamiento) era el opuesto — como sería el caso español: incluso se ha sostenido que los notarios españoles «carecían de competencia para autorizar la elección notarial de la ley aplicable» ${ }^{103}$.

52. Menos convincentes son los pronunciamientos que siguen, en el FD 6. Comenzando por el final: la referencia al apdo. 4 del art. 83 choca con el resto de los desarrollos del texto. La DGRN parece convencida de que el causante efectuó una elección ${ }^{104}$; pero de ser ese el caso, por lo que vimos el supuesto no sería uno del art. 83.4, ya que en este el punto de partida es, justamente, que no ha habido elección.

53. Resultan también dudosas las afirmaciones sobre la professio iuris misma: carece de una apoyatura suficiente, y no se indaga en su extensión. A propósito de lo primero, la DGRN se limita a recordar lo que dice el Reglamento en su art. 22 y en sus cdos. 39 y 40 sobre la elección no expresa, y se da por satisfecha - en el sentido de que ha habido elección- por el mero hecho de que disponer mortis causa a favor de la esposa corresponde «al tipo de frecuencia de los testamentos británicos» ${ }^{105}$ (FD 6). El razonamiento es pobre. Se suma que la doctrina ha concluido lo contrario ante supuestos

103 Carrascosa González, J., loc. cit., nota 5, párr. 70.

104 Véase el mismo FD 6, y el 8.

105 Álvarez GonzÁlez, S., en su «Nota» a la STS de 12 de enero de 2015, REDI, 2015 (2), pp. 235238, califica también la situación de sucesión de nacional del Reino Unido (inglés) con último domicilio en España y con testamento instituyendo a su esposa como única heredera de todos los bienes, derechos y acciones localizados en España, como un «supuesto de hecho [que] no puede ser más típico». 
idénticos: en algún caso sin mayores argumentos ${ }^{106}$; en otro a la luz de un elemento que ahora también se da, como es la cláusula de salvaguarda de las legítimas. Se indica en este sentido que: «Probablemente se trate de una mera cláusula de estilo introducida por el notario con el objetivo de evitar la preterición [...] bajo la eventual aplicación de una ley que — contrariamente a la nacional del testador - contemplase tales realidades jurídicas (la legítima y la preterición)», pero que trae consecuencias: «El contenido del testamento salvando las legítimas no parece indicar una clara y contundente afirmación de la libertad de testar que el causante ostentaría conforme a su ley nacional»; «[no] ha mediado professio iuris a favor de la ley nacional del causante (art. 22 del Reglamento). Aunque tal elección de ley puede ser tanto expresa como tácita [...], ya señalé [...] que el contenido del testamento se corresponde con un testamento sometido a un sistema como el del CC. La alusión a la salvaguarda de las legítimas imposibilita concluir que hay elección tácita de la ley inglesa» ${ }^{107}$.

54. La DGRN no investiga la extensión de la optio iuris, a pesar de que el testamento se limita a los bienes que se hallen en España ${ }^{108}$. Ello no es irrelevante, porque en el marco del Reglamento, art. 22, la elección de ley solo es válida si es total; en otro caso cabe aún, mas limitada a la admisibilidad y validez material (y formal, a tenor del art. 83.3) de la disposición mortis causa.

55. A tenor de su FD 2, en marzo de 2018 la DGRN aprecia elección de ley por el causante en el testamento otorgado ante notario español en 2004 por dos motivos: la redacción del documento a doble columna en lenguas inglesa y española ${ }^{109}$, y la mención a que se otorgaba conforme a la ley personal (como no podía ser de otra manera, por virtud del art. 9.8 CC). De nuevo, una argumentación pobre.

\subsubsection{La Resolución de 10 de abril de 2017}

56. El parecido entre los supuestos en la base de esta resolución y las de 2016 explican que la registradora concluyera la aplicación de la ley alemana, con apoyo expreso en las resoluciones previas: el título testamentario fue vehículo para el establecimiento de la professio iuris; el testador alemán eligió su ley nacional. La DGRN, en el FD 4, en cambio, optó por un razonamiento distinto: califica el problema expresamente como cuestión de interpretación del testamento, e indica que la misma ha de hacerse a la luz de la ley hipotéticamente aplicable (la que ostentará este título si el testamento es válido),

\footnotetext{
106 CARrascosa GonZÁlez, J., op. cit., nota 14, párr. 167 en p. 278.

107 Álvarez González, S., loc. últ. cit. Podríamos decir que la presencia de la cláusula actúa como contrapeso al argumento de la DGRN —el «tipo de frecuencia»-.

108 Al dato del testamento parcial alude la DGRN en el FD 9, pero desde una óptica distinta: la de si es posible la división de los títulos testamentarios una vez en vigor el Reglamento. Contra lo que parece entender la DGRN, ello no atenta de forma automática contra la unidad de la sucesión MARIÑo PARDO, F. M., loc. cit., nota 1. También lo sugiere Álvarez GonzÁLEZ, A., loc. últ. cit.

109 Véase supra nota 16.
} 
que, a su juicio, es la de la residencia habitual (art. 21). Hay aquí, a nuestro juicio, varios datos discutibles: de entrada, los criterios de interpretación a fin de determinar si ha habido elección de ley han de ser en primer término los que aporta el Reglamento, y no los de la ley aplicable ${ }^{110}$. En segundo lugar, la ley hipotéticamente aplicable es la presuntamente elegida, y no la que se aplicaría en defecto de elección ${ }^{111}$. Finalmente, la DGRN concluye que no ha habido elección sin mayor argumentación ${ }^{112}$, y desde luego sin intervención alguna del Derecho español de la residencia habitual que ella misma ha declarado aplicable para interpretar el testamento.

57. Con independencia de que en el fondo es esta resolución la que nos parece correcta, y no las otras, es de lamentar la falta de unidad en la manera de afrontar el problema de la ley aplicable a los testamentos previos al 17 de agosto de 2015; y en general, en la búsqueda de una elección no explícita. A nuestro juicio, cuando el sistema vigente en el momento de otorgar el testamento es igual o semejante al de nuestro Código Civil, y especialmente si ha intervenido un fedatario al que el ordenamiento confía la protección de la legalidad de los actos ${ }^{113}$, la búsqueda de una elección de ley está irremediablemente presidida por la presunción de que no existe, porque no podía (legalmente) existir ${ }^{114}$. La interpretación de las Resoluciones de 2016 -y la de 2018-, con su escaso fundamento, resulta demasiado generosa; y lo es sin necesidad, porque podría haber llegado a idéntico resultado con apoyo en el apdo. 4 del art. 83, es decir, a través de una ficción de elección ${ }^{115}$. Un precepto que, por cierto, se echa en falta en la Resolución de 10 de abril de 2017.

58. Tampoco se entiende $-\mathrm{y}$ menos aún a la luz de la generosidad aludida - cuál ha sido el elemento determinante del resultado distinto en la Resolución de abril de 2017. La nacionalidad alemana (y no inglesa) del testador, sin más, no puede serlo; tampoco el contenido de la ley nacional, por cuanto justamente faltaba la prueba del Derecho alemán cuya elección se discute ${ }^{116}$. Solo la diferencia en las fechas de otorgamiento de los testamentos en la base de una y otras resoluciones podría ser relevante: al fin y al cabo, en septiembre de 2014, cuando se redacta el testamento del causante de nacionalidad alemana, el notario ya podía jugar con la nueva normativa, aunque faltaba

110 Supra, párrs. 8 y ss.

111 Nota anterior; también Frank, S., «Art. 22«, en GeImer, R. y SchÜtZe, R. A., Internationaler Rechtsverkehr in Zivil- und Handelssachen, Munich, C. H. Beck, Band III, 2018, párr. 27.

${ }_{112}$ FD 4: «Solo de resultar una professio iuris expresa o indubitada en sus términos -lo que no ocurre-》.

113 Aunque existen por supuesto dudas sobre cuál debe ser el alcance del asesoramiento.

${ }^{114}$ La voluntad del testador como hecho podría existir, pero sería irrelevante a los ojos del ordenamiento del otorgamiento, que la consideraría —-más que inexistente—inválida.

115 Véase supra, párr. 24, sobre el recurso al art. 83.4 cuando una elección de ley no es evidente, especialmente porque no habría sido posible al amparo del sistema de DIPr aplicable al tiempo de otorgarse el testamento o disposición mortis causa.

116 En el marco del art. 83 cabe hacer depender la elección de ley de que la disposición que la vehicula sea válida a la luz del ordenamiento presuntamente elegido, porque tal validez sugiere (¿ratifica?) que efectivamente el testador quiso aplicar esa ley. Sin embargo, en ninguna de las resoluciones en juego se analiza la validez del testamento en cuanto al fondo. 
casi un año para su aplicabilidad plena. No obstante, no trasciende del texto que este sea el motivo por el cual la DGRN ha afrontado la elección de ley de una forma diferente en este caso ${ }^{117}$.

\section{CONCLUSIÓN}

61. El Reglamento 650/2012, en vigor desde el 17 de agosto de 2012, es aplicable desde el 17 de agosto de 2015 a las sucesiones que se abran en o tras esa fecha, abarcando también el caso en que exista una disposición mortis causa otorgada anteriormente. Es por ello por lo que su art. 83 será en estos primeros años de vigencia una regla a la que habrá que recurrir con frecuencia. Las dificultades que plantea la comprensión del texto hacen pensar que será necesaria la interpretación por parte del TJUE.

62. En España existen ya varios supuestos de aplicación por parte de la DGRN de la disposición mencionada. Debido a la remisión que desde la misma se hace a otros preceptos del Reglamento - en particular el relativo a la elección de ley por el causante- estos entran en juego, y tenemos una primera impresión sobre cómo son comprendidos por nuestros operadores jurídicos. En este sentido, más allá de la valoración que las resoluciones de la DGRN que hemos analizado merecen en su solución concreta, es oportuno resaltar cómo la DGRN plasma su actitud de cara al nuevo régimen y su voluntad de promover su correcta aplicación por aquellos a quienes vincula (en primera línea, notarios y registradores). Remitimos en este sentido a la lectura de los FFDD 4, 5 o 7 de la Resolución de 15 de junio de 2016: sobre el rol actual del art. 9.8 CC; sobre el carácter no absoluto de la conexión a la residencia habitual; sobre el antecedente en el Convenio de La Haya de 1989. Las afirmaciones, si bien innecesarias para los casos concretos y no todas ellas correctas (o compartidas), indican a nuestro juicio dos rasgos muy valorables: la atención prestada al sistema ${ }^{118}$, y la intención, pedagógica si se quiere, de hacerlo visible y comunicarlo. En la misma línea va el recordatorio a las obligaciones del notario a raíz de la puesta en marcha del sistema europeo, más complejo que el precedente, y que obliga a identificar en cada caso el carácter internacional de la sucesión; la residencia habitual del causante; y si ha habido professio iuris.

117 Excepto que quiera leerse entre líneas en el recordatorio al final del FD 3, sobre la diligencia del notario: porque la professio iuris no expresa debe resultar de los términos de la disposición mortis causa, el notario debe establecer en abstracto la ley aplicable a la sucesión, y en concreto los elementos relevantes al caso.

${ }_{118}$ Las resoluciones plantean — aunque no necesariamente para abordar, o resolver- algunos otros problemas que sin duda surgirán en la práctica del Reglamento, como es el del reenvío. 


\section{RESUMEN}

\section{EL TIEMPO EN EL REGLAMENTO 650/2012. ILUSTRACIONES DE LA PRÁCTICA ESPAÑOLA}

Los primeros casos de aplicación del Reglamento europeo de sucesiones en España han recaído sobre disposiciones testamentarias otorgadas antes del 17 de agosto de 2015 por extranjeros residentes en España. Las dudas entre los operadores jurídicos involucrados a propósito de la ley aplicable, y en particular, sobre la identificación de una elección de ley, se enmarcan en el art. 83 (disposiciones transitorias). El estudio se centra primero en esta norma ciertamente compleja y trata de explicarla, y pasa luego a evaluar las decisiones españolas a la luz de la misma.

Palabras clave: Reglamento de Sucesiones, elección de ley, art. 83, disposiciones transitorias, Dirección General de los Registros y del Notariado.

\section{ABSTRACT \\ TIME IN THE REGULATION 650/2012. FIRST ILLUSTRATIONS OF SPANISH PRACTICE}

The first cases of application of the European Successions Regulation in Spain dealt with testamentary dispositions granted before August 17, 2015 by foreigners with habitual residence in Spain. The application of art. 83 (transitional provisions) raised doubts among the legal practitioners involved as to the applicable law, in particular regarding the identification of a choice of law. The paper focuses on art. 83 and its complexity; at a second stage it assesses the Spanish decisions in light of the proposed explanations to the rule.

Keywords: Successions Regulation, choice of law, art. 83, transitional provisions, Directorate General for Registers and Notaries. 